\title{
Evaluation of Laboratory Findings and Mortality in Elderly Patients with Acute Biliary Pancreatitis
}

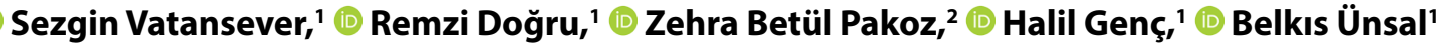 \\ 'Department of Gastroenterology, Katip Çelebi University, Atatürk Training and Research Hospital, İzmir, Turkey \\ ${ }^{2}$ Department of Gastroenterology, Health Sciences University, Tepecik Training and Research Hospital, İzmir, Turkey
}

\begin{abstract}
Objectives: Gallstones are the most common cause of acute biliary pancreatitis. Laboratory and imaging findings as well as age are important predictors for mortality. Hospitalization rate is also higher in elderly patients. In this study, we investigated clinical parameters and total mortality in patients with acute pancreatitis aged $>65$ years.

Methods: In this study, 852 patients who entered the Gastroenterology Clinic for acute biliary pancreatitis between April 2006 and October 2013 were included. Data were retrospectively collected from the electronic record system. The patients with elevated aspartate aminotransferase levels (i.e. three times higher than normal value), cholelithiasis, cholecystectomy history, or choledocholithiasis were accepted as the patients with acute biliary pancreatitis. Patients were divided into two groups based on their age, i.e., $>65$ and $<65$ years.

Results: In the group with patients aged $<65$ years, serum alanine aminotransferase, albumin, hematocrit, and amylase, and in the group with patients aged $>65$ years, urea, leukocyte, and C-reactive protein levels were significantly different. Median hospital stay was similar in both the groups. The rate of detection of choledocholithiasis was significantly higher in elderly patients $(p<0.001)$. Mortality rate was significantly higher in elderly patients for 28 day $(0.21 \%$ and $2.95 \%, p<0.001)$ and 90 day $(1.25 \%$ and $5.63 \%$, $\mathrm{p}<0.001)$. In logistic regression multivariate analysis, age (OR 2.0,95\% Cl 1.54-1.36; $\mathrm{p}=0.006)$, elevated urea levels (OR $1.12,95 \% \mathrm{Cl}$ 1.05-1.19; $\mathrm{p}=0.001$ ), elevated hematocrit levels (OR 1.42,95\% $\mathrm{Cl} 1.13-1.77 ; \mathrm{p}=0.002)$, and decreased albumin levels (OR $0.05,95 \%$ $\mathrm{Cl} 0.004-0.652 ; \mathrm{p}=0.022$ ) were found predictors for 90 -day mortality.

Conclusion: Laboratory findings in elderly patients with acute pancreatitis may differ from those in younger patients. Although radiological findings are similar in both the groups, mortality is higher in the group with patients aged $>65$ years.

Keywords: Acute pancreatitis; mortality; elderly.

Please cite this article as "Vatansever S, Doğru R, Pakoz ZB, Genç H, Ünsal B. Evaluation of Laboratory Findings and Mortality in Elderly Patients with Acute Biliary Pancreatitis. Med Bull Sisli Etfal Hosp 2018;52(4):274-278".
\end{abstract}

A cute pancreatitis (AP) is one of the most common diseases of the gastrointestinal tract. The most common cause of AP is gallstone. In addition, alcohol, hypertriglyceridemia, drugs, genetic factors, hypercalcemia, autoimmunity, and pancreatitis due to ERCP (Endoscopic Retrograde Cholangio-Pancreatography) may develop. ${ }^{[1,2]}$ AP incurs serious physical, emotional, and financial burden. ${ }^{[1]}$ In the US, it is responsible for roughly 330.000 emergency service and 240.000 hospital admissions each year, and its incidence is increasing worldwide. ${ }^{[3]}$ The annual incidence ranges from 4.9 to 35 per 100.000 patients. ${ }^{[4]}$ In the US, the annual cost incurred by AP is $\$ 2.5$ billion. ${ }^{[3]}$ Approximately $80 \%$ of the AP cases had a mild and $20 \%$ had a severe course. ${ }^{[2]}$

Sometimes diagnosis of moderate and very severe AP is

Address for correspondence: Zehra Betul Pakoz, MD. Tepecik Eğitim ve Araştırma Hastanesi, Gastroenteroloji Kliniği, İzmir Phone: +90 5055250509 E-mail: betulpakoz@yahoo.com

Submitted Date: September 13, 2018 Accepted Date: September 25, 2018 Available Online Date: December 26, 2018

${ }^{\circ}$ Copyright 2018 by The Medical Bulletin of Sisli Etfal Hospital - Available online at www.sislietfaltip.org

This is an open access article under the CC BY-NC-ND license (http://creativecommons.org/licenses/by-nc/4.0/). 
delayed. This may cause deaths due to inability to detect preventable causes, and development of secondary attacks. While mortality is very low in interstitial pancreatitis, it increases up to $10 \%$ in necrotizing pancreatitis and $30 \%-$ $40 \%$ in infected necrosis. ${ }^{[5-7]}$ The AP-related mortality shows bimodal distribution. Early death occurs due to severe and irreversible multiorgan dysfunction, and late-term deaths are caused by disease-induced sepsis and subsequent organ failure. ${ }^{[8]}$ Various scoring systems are available to evaluate AP severity. While clinical and laboratory data are used together with Ranson, APACHE II, and Atlanta scores, the Balthazar scoring is used radiologically. ${ }^{[9-11]}$

Large-scale cohort studies show that the group with the highest rate of hospitalization due to AP is the elderly population. ${ }^{[12]}$ Some studies have demonstrated increased APrelated mortality and co-morbidity in elderly patients. ${ }^{[13]}$ In some studies, mortality in elderly patients was found to be similar to that in other age groups. ${ }^{[14,15]}$

Physiology and morphology of organs change with age, which is a natural process. Therefore, the response of metabolism to external factors and diseases also change. The aim of this study was to evaluate the findings and total mortality in patients with acute biliary pancreatitis aged $<65$ and $>65$ years.

\section{Methods}

Between April 2006 and October 2013, 852 patients were enrolled in this study. Data were collected from the electronic registry of the patients, and retrospectively evaluated. The patients were divided into two groups: those aged $<65$ and those $>65$ years. The diagnosis of AP was based on the presence of two of the criteria including typical pancreatic pain, $\geq 3$-fold increased amylase or lipase levels, or AP findings in imaging. Patients with aspartate aminotransferase levels increased up to more than upper limit of normal, those with cholelithiasis, bile duct stone, or biliary pancreatitis, patients with a history of cholecystectomy were accepted as patients with biliary pancreatitis. Patients with a history of alcohol use, high triglyceride and calcium levels, those using a new drug before the attack, and those presented with AP for the second time were excluded from the study.

In addition, patients who were referred from another center due to severe pancreatitis and complicated pancreatitis and those who received treatment at the center where they were referred from for more than two days were excluded from this study. All the patients were screened with abdominal ultrasound (USG), endosonography (EUS), or magnetic resonance cholangiopancreatography (MRCP) for choledocholithiasis. ERCP was performed to those who had choledochal stone. In accordance with the AP treatment guidelines, all patients were firstly given fluid therapy. In patients with recurrent febrile episodes, despite antibiotherapy, wide spectrum antibiotics and/or antifungals were added to their treatment. All patients were hospitalized, followed up, and treated. Those with signs of clinical and laboratory recovery were discharged.

The Balthazar scoring used in radiological imaging was divided into two groups: mild and severe. Balthazar score of A-C and computed tomography (CT) severity index of 1-5 were taken as an indication of mild pancreatitis. Balthazar score D-E and CT severity index of 6-10 were taken as an indication of severe pancreatitis. Our study was conducted in accordance with the principles of the Declaration of Helsinki, and the ethics committee approval was obtained.

\section{Statistical Analysis}

Statistical analysis of the study was performed with the SPSS 17 package software. Data were expressed as mean and standard deviation. The chi-square test was used for categorical variables. The normality and homogeneity of the groups were evaluated. The Mann-Whitney $U$ test was used for data not consistent with normal distribution. Data with normal distribution were evaluated using Student $t$ test. After the logistic regression univariate analysis was performed to evaluate mortality, the $p$ values below 0.1 and independent of each other were taken into the multivariate analysis to create a model. A $p$ value of $<0.05$ was considered significant.

\section{Results}

In the study, mean ages were 38 and 75 years in groups with patients aged $<65$ and $>65$ years, respectively. Demographic and laboratory data of the patients are given in Table 1. Alanine aminotransferase, albumin, hematocrit, and amylase levels were found to be significantly higher in younger people, whereas urea, leukocyte, and C-reactive protein levels were significantly higher in the elderly. The mean hospital stay was similar in both groups. The rate of detection of choledochal stones was found to be significantly higher in the elderly (Table 1). Balthazar scores were similar in both the groups (Table 2).

Mortality rates were evaluated on the $28^{\text {th }}$ day and $90^{\text {th }}$ day. Mortality rates on the $28^{\text {th }}$ day and $90^{\text {th }}$ day in patients aged $>65$ years were significantly higher than those in the younger age group (Table 3 ).

In addition, in the multivariate logistic regression analysis, increase in age, urea, and hematocrit, and decrease in albumin levels were found to be predictive of mortality on day 90 (Table 4). Although in the univariate logistic regres- 
Table 1. Laboratory and imaging findings of the patients $<65$ and $>65$ years

\begin{tabular}{|c|c|c|c|}
\hline & $\begin{array}{c}<65 \text { years } \\
(n=479)\end{array}$ & $\begin{array}{c}>65 \text { years } \\
(n=373)\end{array}$ & $\mathbf{p}$ \\
\hline Age & $38(18-64)$ & $75(65-95)$ & $<0.001$ \\
\hline AST & $104(10-1599)$ & $108.5(3-3633)$ & 0.354 \\
\hline ALT & $177(12-682)$ & $127.5(9-543)$ & 0.029 \\
\hline ALP & $120(62-601)$ & $141(52-1346)$ & 0.338 \\
\hline Total bilirubin & $2.4(0.2-34)$ & $2.9(0.3-23)$ & 0.183 \\
\hline Albumin & $3.8 \pm 0.5$ & $3.6 \pm 0.5$ & $<0.001$ \\
\hline Amylase & $1300(350-8776)$ & $1099(350-5400)$ & 0.005 \\
\hline Glucose & $111(47-700)$ & $112(42-729)$ & 0.236 \\
\hline $\mathrm{LDH}$ & $222(99-3325)$ & $206(91-1333)$ & 0.391 \\
\hline Urea & $12(4-59)$ & $18.5(4-98)$ & $<0.001$ \\
\hline Calcium & $9 \pm 0.7$ & $8.8 \pm 0.7$ & $<0.001$ \\
\hline Hematocrit & $37.8 \pm 4.3$ & $36 \pm 5$ & $<0.001$ \\
\hline Duration of hospitalization (day) & $6(1-32)$ & $6(1-52)$ & 0.48 \\
\hline Choledochal stone & $41 / 479$ & $73 / 373$ & $<0.001$ \\
\hline Size of choledochal stone (mm) & $8(3-20)$ & $10(3-45)$ & 0.091 \\
\hline Number of choledochal stone & $2(1-5)$ & $1(1-5)$ & 0.696 \\
\hline Ratio of multiple choledochal stones & $21 / 41$ & $33 / 73$ & 0.59 \\
\hline History of cholelithiasis + cholecystectomy & $415(86.6)$ & $313(83.9)$ & 0.76 \\
\hline Presence of cholelithiasis + cholecystectomy at admission & $80 / 335$ & $49 / 264$ & 0.239 \\
\hline
\end{tabular}

AST: Aspartate aminotransferase; ALT: Alanine aminotransferase; ALP: Alkaline phosphatase; GGT: Gamma- glutamyl transferase; LDH: Lactate dehydrogenase; CRP; C-reactive protein.

Table 2. Comparison between the Balthazar score and CT severity index score

\begin{tabular}{lccc}
\hline & $<65$ years & $>65$ years & p \\
\hline Balthazar score & & & 0.239 \\
Mild pancreatitis (A, B, C) & $411(85.8)$ & $336(90)$ & \\
Severe pancreatitis (D, E) & $68(14.2)$ & $37(10)$ & \\
CT severity index & & & 0.873 \\
Mild pancreatitis (0-3) & $450(94)$ & $352(94.6)$ & \\
Severe pancreatitis (4-10) & $29(6)$ & $21(5.6)$ & \\
\hline CT: Computed tomography. & & & \\
\hline
\end{tabular}

Table 3. Total mortality rates on days 28 and 90 in patients $<65$ and $>65$ years (chi-square test)

\begin{tabular}{lccc}
\hline & $<65$ years & $>65$ years & $\mathbf{p}$ \\
\hline 28 day & 0.21 & 2.95 & 0.001 \\
90 day & 1.25 & 5.63 & 0.001 \\
\hline
\end{tabular}

sion analysis, $\mathrm{CT}$ severity index was found to be significant in predicting 90-day AP mortality (OR 4.88, 95\% Cl 1. 51$15.77 ; p=0.008$ ), in the multivariate logistic regression anal$y s i s$, it was not detected to be an independent predictor in predicting AP mortality at 90 days $(p=0.279)$.
Table 4. Multivariate logistic regression analysis for the prediction of 90-day mortality

\begin{tabular}{lcccccc}
\hline & B & Wald & p & OR & $\begin{array}{c}\text { Lower } \\
\text { limit }\end{array}$ & $\begin{array}{c}\text { Upper } \\
\text { limit }\end{array}$ \\
\hline Age & 0.180 & 7.705 & 0.006 & 1.198 & 1.054 & 1.360 \\
Hematocrit & 0.348 & 9.344 & 0.002 & 1.416 & 1.133 & 1.771 \\
CRP & 0.076 & 3.137 & 0.077 & 1.079 & 0.992 & 1.173 \\
AST & $<0.001$ & 0.032 & 0.857 & 1.000 & 0.997 & 1.004 \\
Albumin & -3.009 & 5.219 & 0.022 & 0.049 & 0.004 & 0.652 \\
Urea & 0.111 & 110.271 & 0.001 & 1.117 & 1.047 & 1.192 \\
CT severity & 1.340 & 1.170 & 0.279 & 30.819 & 0.337 & 43.318 \\
index & & & & & &
\end{tabular}

CRP: C-reactive protein; AST: Aspartate aminotransferase; CT: Computed tomography.

\section{Discussion}

With the increase in the average life expectancy, the number of elderly people is also increasing in societies. ${ }^{[16]}$ Therefore, the course of the disease has been investigated increasingly in the elderly. Previous studies indicate that severe $A P$ is an important cause of morbidity and mortality in elderly patients. Xin et al. ${ }^{[17]}$ found mortality rate of $17 \%$ in 
elderly patients with severe AP.

Among 212 patients with acute biliary pancreatitis, Roulin et al. ${ }^{[15]}$ found similar 90 -day mortality rates in the groups with patients $<70$ and $>70$ years. Similarly, in the study of Kim et al., ${ }^{[18]}$ the progression of AP was investigated in patients who were aged $<65$ and $>65$ years, and no significant difference was found between the two groups in terms of mortality and complications. Patel et al. ${ }^{[19]}$ found higher mortality rates in the elderly group. Yadav et al. ${ }^{[13]}$ examined 18 publications related to AP, and they found that mortality increased with age. In our study, mortality rates on the $28^{\text {th }}$ and $90^{\text {th }}$ day in patients $>65$ years of age were found to be significantly higher than those aged $<65$ years. In the multivariate logistic regression analysis, age was found to be an independent predictor of mortality.

Numerous studies show that the Balthazar scoring is successful in predicting the prognosis of AP. ${ }^{[20,21]}$ Mortality rates were found to be $8 \%-17 \%$ higher in severe pancreatitis based on CT severity index relative to previous studies. ${ }^{[22,23]}$ In our study, no difference was found in the patients with acute biliary pancreatitis aged $<65$ and $>65$ years according to the Balthazar scoring and CT severity index. In multivariate logistic regression analysis, tomography findings were not found to be an independent variable in predicting mortality. This may be because the factor that increases mortality in the geriatric group is other accompanying diseases. In addition, the low number of patients with mortality may have caused the CT severity index not to be detected significantly. Previous studies show that the inflammatory response in the elderly population is less than that of young people. ${ }^{[24]}$ In our study, leukocyte and CRP elevation, decrease in albumin levels was significantly different in geriatric patients.

In our study, the rate of choledochal stones was found to be significantly higher in patients aged $>65$ years. Biliary diseases are more common in the elderly. Similar to previous studies, biliary stones responsible for etiology were more frequently found in the common bile duct. This situation is because the stones are smaller and have higher clearance in the common bile duct in the younger age group. ${ }^{[13,25,26]}$

The most important limitation of our study was that APACHE-2 and Ranson scores could not be used together. In addition, detailed evaluation of comorbidities might play a more effective role in predicting mortality. Another limitation was that our study was a single-center and retrospective study. Today, the maintenance and treatment of geriatric patients has become more important as the population of the geriatric population increases. Our study has the largest number of patients in the literature comparing geriatric patients with acute biliary pancreatitis.
In our study, the AP-related mortality rates were found to be higher in patients $>65$ years. Detailed and prospective studies may be more enlightening.

\section{Disclosures}

Ethics Committee Approval: The study was approved by the Local Ethics Committee.

Peer-review: Externally peer-reviewed.

Conflict of Interest: None declared.

Authorship contributions: Concept - S.V., R.D.; Design - S.V., H.G., R.D.; Supervision - B.U.; Materials - S.V., R.D., H.G.; Data collection \&/ or processing - Z.B.P.; Analysis and/or interpretation - S.V.; Literature search - Z.B.P., H.G.; Writing - Z.B.P.; Critical review - B.U.

\section{References}

1. Tenner S, Baillie J, DeWitt J, Vege SS; American College of Gastroenterology. American College of Gastroenterology guideline: management of acute pancreatitis. Am J Gastroenterol 2013;108:1400-15; 1416.

2. Banks PA, Bollen TL, Dervenis C, Gooszen HG, Johnson CD, Sarr $M G$, et al; Acute Pancreatitis Classification Working Group. Classification of acute pancreatitis--2012: revision of the Atlanta classification and definitions by international consensus. Gut 2013;62:102-11. [CrossRef]

3. Peery AF, Crockett SD, Barritt AS, Dellon ES, Eluri S, Gangarosa LM, et al. Burden of Gastrointestinal, Liver, and Pancreatic Diseases in the United States. Gastroenterology 2015;149:1731-41. [CrossRef]

4. Fagenholz PJ, Fernández-del Castillo C, Harris NS, Pelletier AJ, Camargo CA Jr. Direct medical costs of acute pancreatitis hospitalizations in the United States. Pancreas 2007;35:302-7. [CrossRef]

5. Busquets J, Fabregat J, Pelaez N, Millan M, Secanella L, GarciaBorobia $\mathrm{F}$, et al. Factors influencing mortality in patients undergoing surgery for acute pancreatitis: importance of peripancreatic tissue and fluid infection. Pancreas 2013;42:285-92. [CrossRef]

6. Marshall JC, Cook DJ, Christou NV, Bernard GR, Sprung CL, Sibbald WJ. Multiple organ dysfunction score: a reliable descriptor of a complex clinical outcome. Crit Care Med 1995;23:1638-52. [CrossRef]

7. Tenner S, Sica G, Hughes M, Noordhoek E, Feng S, Zinner M, et al. Relationship of necrosis to organ failure in severe acute pancreatitis. Gastroenterology 1997;113:899-903. [CrossRef]

8. Abu-Zidan FM, Bonham MJ, Windsor JA. Severity of acute pancreatitis: a multivariate analysis of oxidative stress markers and modified Glasgow criteria. Br J Surg 2000;87:1019-23. [CrossRef]

9. Ranson JH, Rifkind KM, Roses DF, Fink SD, Eng K, Spencer FC. Prognostic signs and the role of operative management in acutepancreatitis. Surg Gynecol Obstet 1974;139:69-81.

10. Balthazar EJ, Robinson DL, Megibow AJ, Ranson JH. Acute pancreatitis: value of $\mathrm{CT}$ in establishing prognosis. Radiology 1990;174:331-6. [CrossRef]

11. Larvin M, McMahon MJ. APACHE-II score for assessment and 
monitoring of acute pancreatitis. Lancet 1989;2:201-5. [CrossRef]

12. Goldacre MJ, Roberts SE. Hospital admission for acute pancreatitis in an English population, 1963-98: database study of incidence and mortality. BMJ 2004;328:1466-9. [CrossRef]

13. Yadav $D$, Lowenfels $A B$. Trends in the epidemiology of the first attack of acute pancreatitis: a systematic review. Pancreas 2006;33:323-30. [CrossRef]

14. Losurdo G, lannone A, Principi M, Barone M, Ranaldo N, lerardi E, et al. Acute pancreatitis in elderly patients: A retrospective evaluation at hospital admission. Eur J Intern Med 2016;30:88-93. [CrossRef]

15. Roulin D, Girardet R, Duran R, Hajdu S, Denys A, Halkic N, et al. Outcome of elderly patients after acute biliary pancreatitis. Biosci Trends 2018;12:54-9. [CrossRef]

16. Ortman JM, Velkoff VA, Hogan H. An Aging Nation: The Older Population in the United States: Population Estimates and Projections Washington, DC: U.S. Census Bureau; May 2014. Available at: https://www.census.gov/prod/2014pubs/p25-1140.pdf. Accessed Nov 1, 2018.

17. Xin MJ, Chen H, Luo B, Sun JB. Severe acute pancreatitis in the elderly: etiology and clinicalcharacteristics. World J Gastroenterol 2008;14:2517-21. [CrossRef]

18. Kim JE, Hwang JH, Lee SH, Cha BH, Park YS, Kim JW, et al. The clinical outcome of elderly patients with acute pancreatitis is not different in spite of the different etiologies and severity. Arch Gerontol Geriatr 2012;54:256-60. [CrossRef]
19. Patel K, Li F, Luthra A, Hinton A, Lara L, Groce R, et al. Acute Biliary Pancreatitis is Associated With Adverse Outcomes in the Elderly: A Propensity Score-Matched Analysis. J Clin Gastroenterol 2018 Aug 28. doi: 10.1097/MCG.0000000000001108. [Epub ahead of print]. [CrossRef]

20. Simchuk EJ, Traverso LW, Nukui Y, Kozarek RA. Computed tomography severity index is a predictor of outcomes for severe pancreatitis. Am J Surg 2000;179:352-5. [CrossRef]

21. Brand $M$, Götz A, Zeman F, Behrens $G$, Leitzmann M, Brünnler $T$, et al. Acute necrotizing pancreatitis: laboratory, clinical, and imagingfindings as predictors of patient outcome. AJR Am J Roentgenol 2014;202:1215-31. [CrossRef]

22. Balthazar EJ, Freeny PC, vanSonnenberg E. Imaging and Interventionin Acute Pancreatitis. Radiology 1994;193:297-306. [CrossRef]

23. Rabeneck L, Feinstein AR, Horwitz RI, Wells CK. A new clinical prognostic staging system for acute pancreatitis. Am J Med 1993;95:61-70. [CrossRef]

24. Carvalho JR, Fernandes SR, Santos P, Moura CM, Antunes T, Velosa J. Acute pancreatitis in the elderly: a cause for increased concern? Eur J Gastroenterol Hepatol 2018;30:337-41.

25. Carroll JK, Herrick B, Gipson T, Lee SP. Acute pancreatitis: diagnosis, prognosis, and treatment. Am Fam Physician 2007;75:1513-20.

26. McMahon MJ, Shefta JR. Physical characteristics of gallstones and the calibre of the cystic ductin patients with acute pancreatitis. $\mathrm{Br}$ J Surg 1980;67:6-9. [CrossRef] 